\title{
A Microcontroller-Based Radiation Monitoring and Warning System
}

\author{
Vasile Buruiană and Mihaela Oprea* \\ Petroleum-Gas University of Ploiesti, Department of Control Engineering, \\ Computers and Electronics, \\ Bd. Bucuresti nr. 39, Ploiesti, 100680, Romania \\ mihaela@upg-ploiesti.ro
}

\begin{abstract}
The quality of life is influenced by the environment quality and one of the major factors that require a continuous monitoring is the level of radiation. This paper presents a microcontroller-based system designated for monitoring the release of subatomic high frequency particles in the gamma ray area. Unlike the related scientific literature, where experiments are based on desktop computers for data processing and remote transmission, this work presents an independent standalone microcontroller-based system which incorporates the standard internet protocols. The measurement data, as well as warning signals, are sent to the decision making factors via a communication channel (such as internet, mobile phone or radio amateur band). Some experimental results are also discussed in the paper.
\end{abstract}

\section{Introduction}

One of the main concerns regarding the quality of the environment, and consequently, the life quality, is related to the environment pollution and the level of radiation, especially, in urban regions, in areas with nuclear power plants, and in other contaminated locations. Due to security reasons, several modern radiation monitoring systems were developed in the last decades, most of them for nuclear plants ([21]). In the recent years a new technology was proposed for the development of intelligent environmental monitoring systems, the wireless sensor networks ([13], [14], [16]). A sensor network is composed by a set of geographically distributed autonomous sensors that monitor physical or environmental conditions and transmit the acquired data to a central location. The main components of a sensors network are the sensor nodes, the base stations and a server that centralize all the results of the network activity. The data transmission is usually made between the components of the network either via satellites or by wireless radio. We have developed a microcontroller-based intelligent monitoring and warning system (introduced and described in [2]) that was applied to environmental monitoring. The system was designed in a holonic view, and it can be used as an independent standalone system or it can be included as a part of a larger intelligent monitoring system. In a particular case, the system can be integrated in a sensors network, either as a sensor node or as a

\footnotetext{
* Corresponding author.
} 
base station. Also, the system is low cost and flexible, and can be adapted to various environmental monitoring applications (e.g. air pollution monitoring, flood monitoring and alert [17], soil pollution monitoring, radiation monitoring etc). In this paper it is presented a microcontroller-based system designated for monitoring the release of subatomic high frequency particles in the gamma ray area. In addition to radiation monitoring, the system also performs remote transmission of data together with the GPS coordinates and the appropriate warning signals.

\section{Radiation Monitoring Systems}

Stationary radiation monitoring and warning systems are used in the environmental protection field for a defined perimeter, for identifying, isolating and later containing of contaminated sources. For example, radiation monitoring is used in industry for high speed grinding machine cutting heads, which incorporate a radioactive element, and the cutting head wear is signaled by an increase in normal background noise. The systems reported in the literature are specific to laboratory environments and consist in a microcontroller-based monitoring unit and a desktop-computer-based data acquisition unit. Paper [6] presents a standalone microcontroller-based radiation monitoring system developed around a Siemens 80535 8-bit microcontroller, without any possibility of remote data transmission. This issue is partially solved in [8] by using a desktop computer and an internet connection. The portable system presented in [15], which is based on an 8-bit AMD-80535 microcontroller, is able to transmit the data remotely by interconnecting it through a serial line to a PC, PDA or a smart phone.

In the last years, some radiation monitoring systems based on wireless sensor networks were reported in the literature. A review of some recent experiments with sensor networks for environmental and agricultural applications is presented in [4]. A mobile wireless sensor network for radiation levels monitoring around and inside a nuclear power plant is proposed in [1]. The design and implementation of a radiation dose monitoring system based on wireless sensor network was recently described in [12]. An overview of sensor networks was made in [7], while detailed discussions on the importance of using sensor networks in earth system science and ecology were reported in several papers such as [8] and [11]. Some other environmental and radiation monitoring systems based on sensor networks were reported in the literature (see e.g. [9], [18], [19], [20]).

In this paper we propose a mobile microcontroller system with internet connection capability, which monitors increases in concentrations of gamma radiations along a preset geographical route. The warning signals, which are generated according to the received data, are sent together with the corresponding GPS coordinates to the Committee of Emergency Situations for taking the appropriate measures.

\section{Description of the Experimental Radiation Monitoring and Warning System}

As shown in Figure 1, the system consists of a mobile, microcontroller-based unit, which is capable to transmit data as SMS text to mobile phone networks, audio and 
data through long-range short wave radioamateur channels, and also to access a wireless internet access point located in receiving range. This particular design also presents an advantage due to a constant data connection between the mobile unit and the end user through the radioamateur channel. Such a digital connection, known as AX.25 packet radio protocol, is a low speed implementation of the TCP/IP designed for long distance communication. Even if the mobile system is located outside the range of a traditional wireless access point, a stable digital communication is still possible by using a high gain unidirectional antenna at end user location.

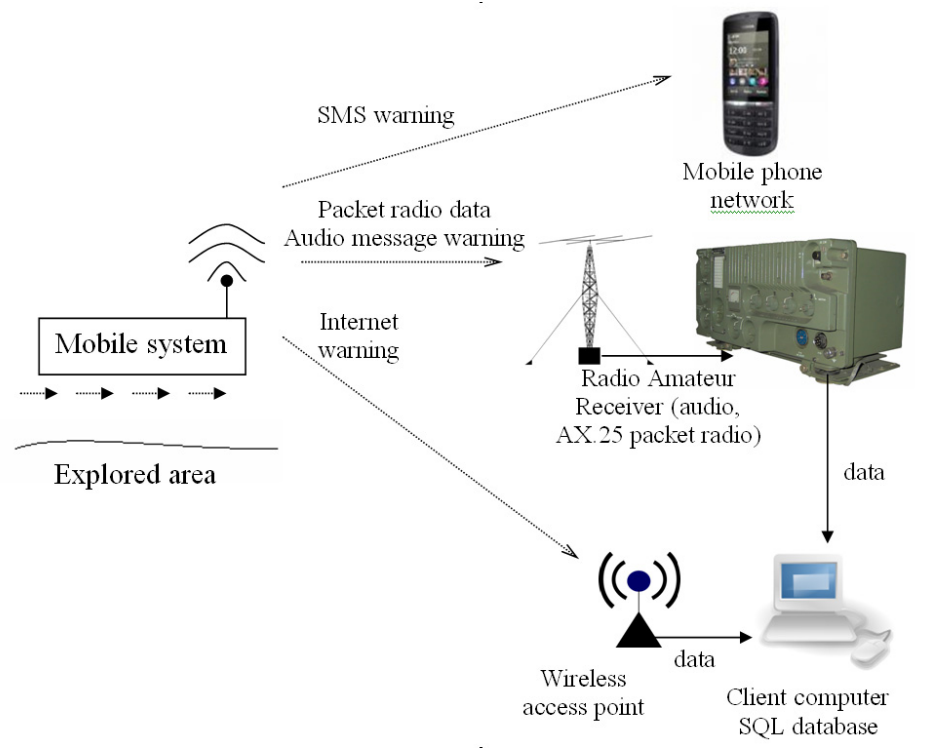

Fig. 1. Schematic representation of the monitoring and warning system

GPS coordinates, radiation measurement and data processing are performed inside the mobile system at microcontroller level, and the values are stored inside a local database. In both cases of internet and packet radio connection, each record is passed to a remote client computer and stored in a SQL database for further analyses. In case of connection disturbances, the acquired data is kept inside the local database for further update. Due to low speed of long range connection, only currently acquired records are passed to the client computer. For large data flows updates between the databases, the wireless internet access point connection is preferred.

The proposed system is based on the BSD Unix-based Data Logger (BSDLog) monitoring and warning system built around the Marvell 88F6281 master microcontroller (proposed in [2]), with the block diagram presented in Figure 2. As interfaces to the environment, the system is equipped with a monitoring interface (IFMON) and a warning interface (IFW), both also built on microcontroller technology. IFMON takes measurements of radiation level through the gamma radiation transducer ( $\mathrm{SG} 1)$. The warning signals (Wa0) will send the coresponding codes to the decision factors remotely through a communication medium: text 
messages via wireless network, internet, GSM modem, or packet data and audio messages through amateur radio channels. As a land mobile system, mechanical shock faults on the system, expecially on its storage memory unit, were solved by adopting a solid state shielded memory stick-type. Also, as a stationary unit, our system is able to issue an internal warning signal (Wa1) to activate the procedure of containment as a direct intervention in the process.

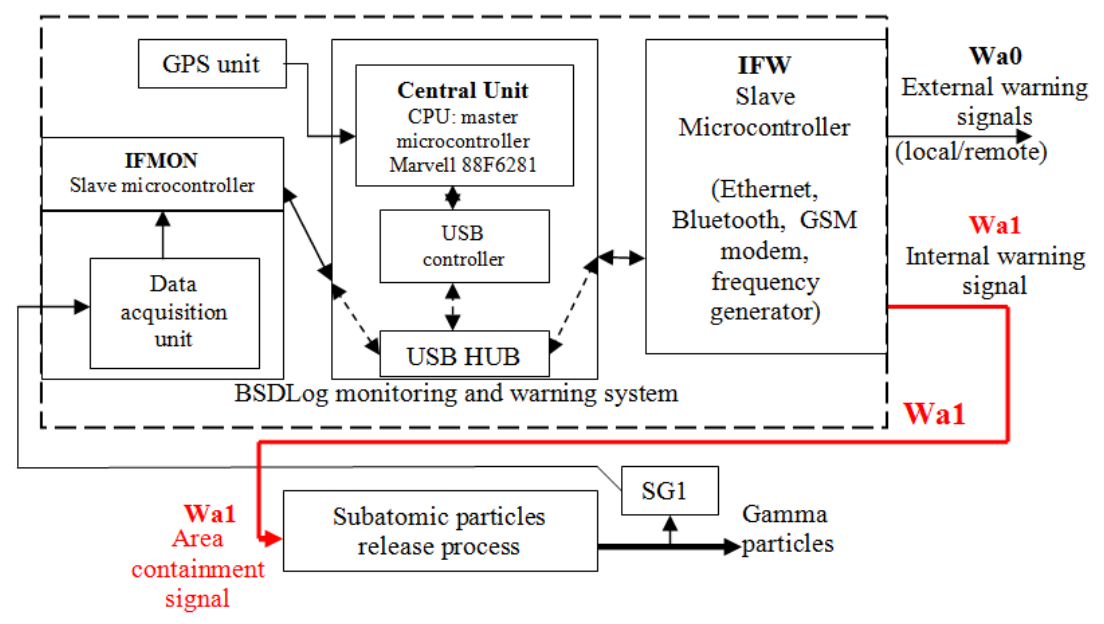

Fig. 2. The block diagram of the microcontroller-based monitoring and warning system

The Marvell 88F6281 microcontroller is built under SoC (System on a Chip) technology for the mobile telephone market, and has a large variety of interfaces (see [22]). For this system we have compiled the Unix 9.0BSD available in the release version (see [23]) using the ARM microcontroller core specifications according to the research work presented in [2], as following:

- most of the compilation output code at BSD Unix kernel and application levels consisted of the microcontroller architecture-proprietary set of instructions, which require less CPU clock counts (a higher speed) for execution;

- malloc() restriction in fixed memory lenghts for all variables, for a better memory access optimisation.

The measurements are taken through the IFMON monitoring interface from the SG1 transducer, constructed around a SBM-19 military-type vacuum chaimber tube Geiger-Muller radiation detecting sensor (see [24]). Previous experiments showed that continuous exposure of silicon-based sensors to radioactive environments lead to atom dislocations and long term ionisations, leading to degrading and structural damage of the silicon semiconductor components, and output electric signal interferences until irreversible damage (see [3]). This reason determined the chosen vacuum chamber sensor approach. The SG1 transducer was built around a PIC16F84 microcontroller and connected to BSDLog as shown in Figure 3. 


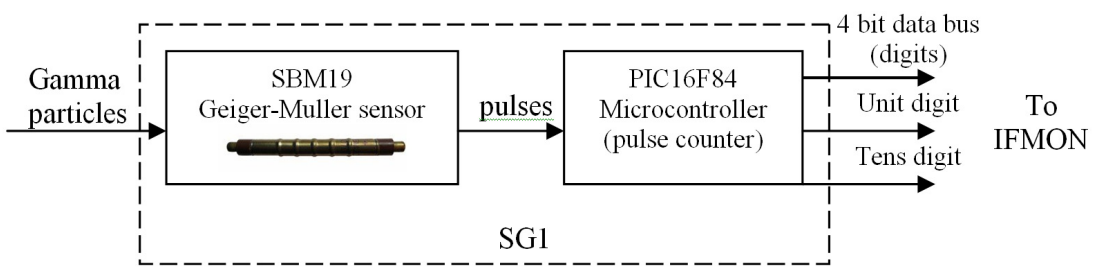

Fig. 3. The SG1 transducer diagram

The SBM19 sensor receives the gamma particles which result from high to low energy decay states of atoms. For each received particle (representing an atom decay), an electric discharge takes place inside the vacuum chamber and a short variation in current intensity is released as an active-high logic signal (pulse). The PIC16F84 microcontroller performs a count of the low to high logic transitions. The resulting value is split in tens and units digits, which are transferred to IFMON via the 4-bit data bus. Also, the microcontroller signals the corresponding digit (tens or units) through two separate logic outputs. To avoid any disturbances in sensor detecting accuracy, special measures were taken in designing its power supply by means of voltage filtering.

The BSDLog main program (presented in Figure 5) communicates with the transducer via Unix pipe according to our designed protocol, presented in Figure 4.

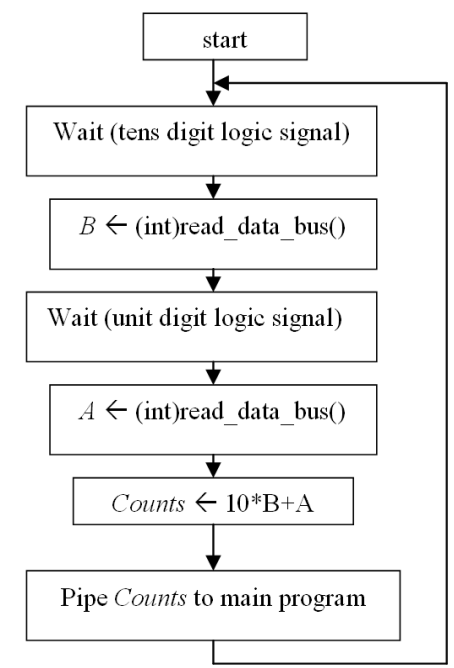

Fig. 4. Radiation transducer communication protocol

The Counts variable represents the number of electric discharges recorded by the transducer in an interval of one second. This variable is continuously updated from the IFMON as soon as the coresponding digits are received through the data bus (see Figure 4), and is passed via the unix pipe system to the main program (see Figure 5). The received radiation pulses count is transformed in radiation dosage according to 
the sensor datasheet, as a number of 19 pulses per second corresponds to a radiation dosage of $1 \mathrm{mRem} / \mathrm{h}$ (see [24]). Three comparations are performed according to the maximum allowed dosage $(0.3 \mathrm{mRem} / \mathrm{h})$, and the ASCII text warning signals are generated as following: ,normal” for natural radiation background, ,warning” for a value closer to the limit, and ,alert" for a dangerous measured level. For each performed measurement, the GPS coordinates are acquired as ASCII text data. In case of a warning or alert, a SMS message is sent through the warning interface via the selected GSM modem adapter (through IFW). Also, our system is capable to convert both the warning signals and the GPS coordinates from ASCII text to synthetised speech by using the BSD Unix flite text to speech utility program (see [25]), for remote audio transmission via radioamateur band on large distances. For this purpose, an UGAR2/R1230 military radio was used in an available Citizen Band channel for both speech and low speed packet data transmission. End-user database updates are performed between the local and remote MySQL servers each time IFW establishes a link to a wireless access point.

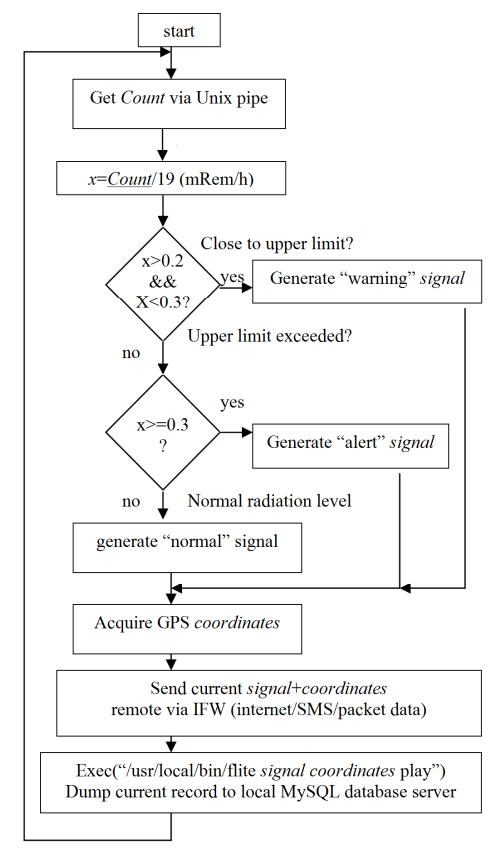

Fig. 5. Radiation monitoring and warning - main program

\section{$4 \quad$ Results and Discussions}

In order to evaluate the performances of our system, we replicated the transducers presented in [8] and [15], and the tests were ran in parallel. Several measurements were performed at the end of year 2010 in the Ploiesti City perimeter. The recorded 
radiation levels and the corresponding warning codes obtained for one of the experiments are shown in Table 1. The recorded coordinates corespond to the CINA medical hospital in Ploiesti City, where at that time a radiography was performed. Our system, as well as the the studied systems, recorded the same variations in the radiation dosages.

Table 1. Recorded radiation levels and corresponding signals

\begin{tabular}{|c|ll|l|}
\hline Date/time & \multicolumn{2}{|c|}{$\begin{array}{c}\text { Radiation level } \\
\text { counts, dosage }\end{array}$} & \multicolumn{1}{c|}{ GPS output, warning code } \\
\hline 20.12 .201015 .15 .22 & 2 & $(0.11 \mathrm{mRem} / \mathrm{h})$ & $151522.000, \mathrm{~A}, 44.95199,26.01102$, normal \\
\hline 20.12 .201015 .15 .23 & 0 & $(0 \mathrm{mRem} / \mathrm{h})$ & $151523.000, \mathrm{~A}, 44.95211,26.01102$, normal \\
\hline 20.12 .201015 .15 .24 & 3 & $(0.16 \mathrm{mRem} / \mathrm{h})$ & $151524.000, \mathrm{~A}, 44.95213,26.01102$, normal \\
\hline 20.12 .201015 .15 .25 & 2 & $(0.11 \mathrm{mRem} / \mathrm{h})$ & $151525.000, \mathrm{~A}, 44.95215,26.01103$, normal \\
\hline 20.12 .201015 .15 .26 & 2 & $(0.11 \mathrm{mRem} / \mathrm{h})$ & $151526.000, \mathrm{~A}, 44.95216,26.01103$, normal \\
\hline 20.12 .201015 .15 .27 & 4 & $(0.21 \mathrm{mRem} / \mathrm{h})$ & $151527.000, \mathrm{~A}, 44.95216,26.01104$, warning \\
\hline 20.12 .201015 .15 .28 & 15 & $(0.8 \mathrm{mRem} / \mathrm{h})$ & $151528.000, \mathrm{~A}, 44.95218,26.01104$, alert \\
\hline 20.12 .201015 .15 .29 & 24 & $(1.27 \mathrm{mRem} / \mathrm{h})$ & $151529.000, \mathrm{~A}, 44.95226,26.01114$, alert \\
\hline 20.12 .201015 .15 .30 & 28 & $(1.47 \mathrm{mRem} / \mathrm{h})$ & $151530.000, \mathrm{~A}, 44.95228,26.01115$, alert \\
\hline 20.12 .201015 .15 .31 & 3 & $(0.16 \mathrm{mRem} / \mathrm{h})$ & $151531.000, \mathrm{~A}, 44.95231,26.01115$, normal \\
\hline 20.12 .201015 .15 .32 & 2 & $(0.11 \mathrm{mRem} / \mathrm{h})$ & $151532.000, \mathrm{~A}, 44.95233,26.01114$, normal \\
\hline 20.12 .201015 .15 .33 & 2 & $(0.11 \mathrm{mRem} / \mathrm{h})$ & $151533.000, \mathrm{~A}, 44.95234,26.01114$, normal \\
\hline 20.12 .201015 .15 .34 & 1 & $(0.1 \mathrm{mRem} / \mathrm{h})$ & $151534.000, \mathrm{~A}, 44.95236,26.01115$, normal \\
\hline 20.12 .201015 .15 .35 & 0 & $(0 \mathrm{mRem} / \mathrm{h})$ & $151535.000, \mathrm{~A}, 44.95237,26.01113$, normal \\
\hline 20.12 .201015 .15 .36 & 3 & $(0.16 \mathrm{mRem} / \mathrm{h})$ & $151536.000, \mathrm{~A}, 44.95239,26.01109$, normal \\
\hline 20.12 .201015 .15 .37 & 2 & $(0.11 \mathrm{mRem} / \mathrm{h})$ & $151537.000, \mathrm{~A}, 44.95241,26.01100$, normal \\
\hline 20.12 .201015 .15 .39 & 2 & $(0 / 11 \mathrm{mRem} / \mathrm{h})$ & $151538.000, \mathrm{~A}, 44.95242,26.00998$, normal \\
\hline
\end{tabular}

The second test consisted in a sudden exposure of the three systems to a weak Americium 241 probe, considering the response time, warning time and recorded radiation level. The resulted data is presented in Table 2.

Table 2. Measured values and recorded time propagation performances

\begin{tabular}{|c|c|c|c|l|l|c|}
\hline \multirow{2}{*}{$\begin{array}{c}\text { Experiment } \\
\text { description }\end{array}$} & \multicolumn{3}{|c|}{ Proposed system performances } & \multicolumn{3}{c|}{ Analysed systems performances } \\
\cline { 2 - 7 } & $\begin{array}{c}\text { TA1 } \\
\text { (s) }\end{array}$ & $\begin{array}{c}\text { TA2 } \\
(\mathrm{ms})\end{array}$ & $\begin{array}{c}\text { level } \\
(\mathrm{mRem} / \mathrm{h})\end{array}$ & $\begin{array}{l}\text { TA1 } \\
\text { (s) }\end{array}$ & $\begin{array}{l}\text { TA2 } \\
(\mathrm{ms})\end{array}$ & $\begin{array}{c}\text { level } \\
(\mathrm{mRem} / \mathrm{h})\end{array}$ \\
\hline $\begin{array}{c}\text { Sudden exposure } \\
\text { to Am241 radiation } \\
\text { probe }\end{array}$ & $1.1 \mathrm{~s}$ & $\begin{array}{c}800 \mathrm{~ms} \\
(\text { wireless })\end{array}$ & 2.8 & $4 \mathrm{~s}$ & $\begin{array}{l}1500 \mathrm{~ms} \\
\text { (wireless) }\end{array}$ & 2.8 \\
\hline $\begin{array}{c}\text { CINA medical } \\
\text { complex area } \\
\text { monitoring }\end{array}$ & $1.1 \mathrm{~s}$ & $\begin{array}{c}800 \mathrm{~ms} \\
\text { (wireless) }\end{array}$ & (see Table 1) & $4 \mathrm{~s}$ & $\begin{array}{l}1700 \mathrm{~ms} \\
\text { (wireless) }\end{array}$ & $\begin{array}{c}0.59 \\
\text { (average) }\end{array}$ \\
\hline
\end{tabular}

$\mathrm{TA}_{1}$ represents the time interval between the beginning of sensor exposure and the release of alert signal at IFW (or PC network interface card). Our proposed system, as well as the replicated systems (see [8], [15]) received and processed the measured data at software level in an interval of time according to relation (1).

$$
\mathrm{TA}_{1}=\mathrm{t}_{\text {exposure }}+\mathrm{t}_{\text {process }}+\mathrm{t}_{\text {transfer_to_output_interface }}
$$


where the variables in (1) are:

- $\quad t_{\text {exposure }}$ represents the 1 second measurement interval (sensor pulses count);

- $t_{\text {process }}$ is the interval of time for data passing through the transducer to its output interface: acquire of gamma particles pulse count, processing at microcontroller level, signal release to output line (IFMON or serial line);

- $\quad t_{\text {transfer_to_output_interface }}$ is the interval of time for data passing from input through the central unit (BSDLog or PC), and updated data packet availability at output (IAV or PC wireless network card).

$\mathrm{TA}_{2}$ represents the propagation interval of the numeric signal from IFW (or PC) to a target desktop computer, connected to the local area network, by encoding the data as a hexadecimal string (pattern) inside a ping packet (see [26]).

During $12^{\text {th }}$ of March and $10^{\text {th }}$ of May 2011, we have performed an atmospheric radiation level monitoring in order to detect any disturbances caused by the Japanese Fukushima nuclear plant. Normal variations in background noise were recorded during this time interval, as confirmed by the study performed in [5].

Our experimental system is presented in Figure 6.

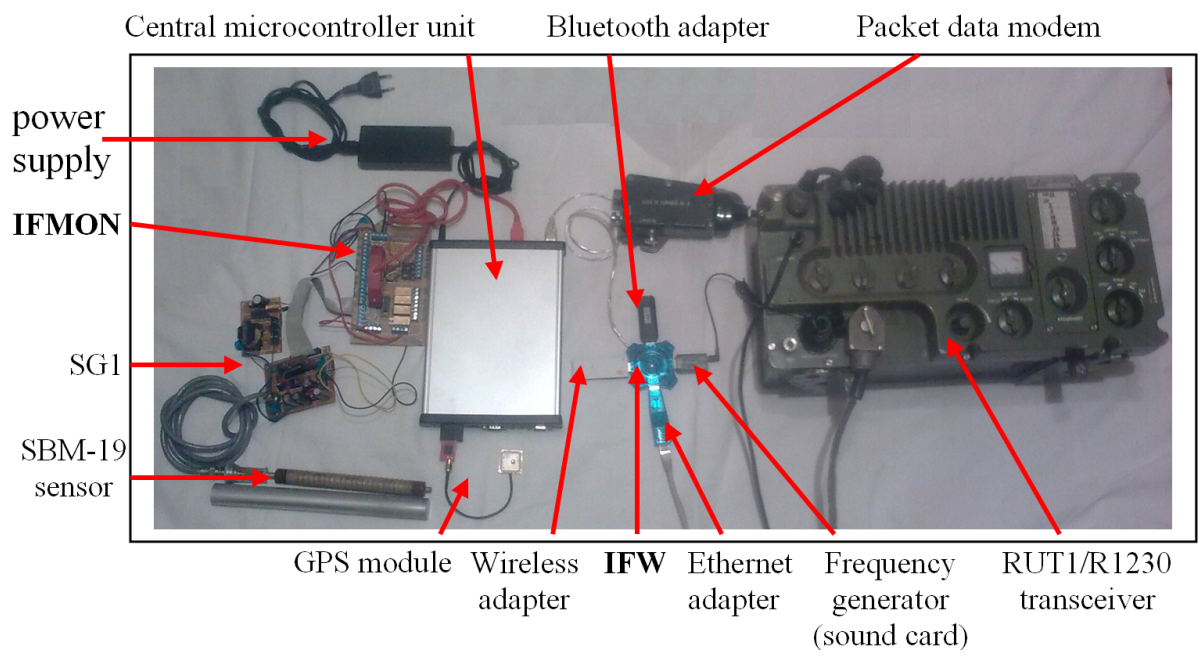

Fig. 6. The experimental system

\section{$5 \quad$ Conclusions and Future Research}

We have presented a microcontroller-based radiation monitoring and warning system with remote data transmission. The performances of the system were tested during several experiments done in selected areas from the Ploieşti City. Also, some comparisons with similar systems were done. The analysed systems, which were based on a Windows XP-based PC, have elaborated the warning signals in an increased interval of time, covering the period from data acquisition to output signal 
release. The same difference is observed in remote data transmission interval, as our proposed system recorded superior performances. In addition to the systems studied in the literature, BSDLog system provided local and remote transmission of the alert signals together with the corresponding GPS coordinates. Our system showed superior response times due to our optimizations of kernel and application level code, and was also capable to maintain a stable data connection to the end-user applcation. Warning signals were transmitted both via SMS messages and internet data packets. For stationary use, it can be adapted for monitoring up to 16 critical points of a fixed perimeter. Also it can monitor a large geographical area by attaching it to a mobile or aerial vehicle. In this case a solar cell panel is used for charging the batteries.

The system can be integrated in an environmental sensor network as sensor node or base station. It can also be extended for other fields of monitoring in environmental protection, such as air quality and toxic gases pollution, with minimum changes in our transducer design. The modular structure of our system allows to interface with other low power transducers based on detectors for toxic and eplosive gases, air quality or contaminating particles (see [10]).

Our future research is focused in attaching the proposed system to a model aircraft and explore geographical area defined by GPS coordinates, for mapping disturbances and establish the hot spots. Further more, solar radiation measurements can be performed with high altitude exploration.

\section{References}

[1] Barbarán, J., Díaz, M., Esteve, I., Rubio, B.: A Mobile Framework for Radiation Monitoring in Nuclear Power Plants, World Academy of Science. Engineering and Technology 27, 160-165 (2007)

[2] Buruiană, V.: Research on the development of a microcontroller-based intelligent monitoring and warning system. PhD Thesis, Department of Control Engineering, Computers and Electronics, Petroleum-Gas University of Ploieşti, Romania (2012)

[3] Buruiană, V.: Wireless Seismic Sensor for Monitoring a Geographical Region. Bulletin of Petroleum-Gas University of Ploieşti - Technical Series LXI(3), 281-286 (2009)

[4] Corke, P., Wark, T., Jurdak, R., Hu, W., Valencia, P., Moore, D.: Environmental Wireless Sensor Networks. Proceedings of the IEEE 98(11), 1903-1917 (2010)

[5] Cosma, C., Iurian, A.R., Nita, D.C., Begy, R.: The presence of radioactive I-131 from Fukushima in north-west of Romania. Journal of Environmental Research and Protection 27, 19-24 (2011),

http: / / www .acoterra-online.ro/files/1321371680.pdf

[6] Cruvinel, P.E., Mascarenhas, S.: An intelligent electret radiation dosimetry system based on a 80535 microcontroller. Nuclear Instruments and Methods in Physics Research Section A: Accelerators, Spectrometers, Detectors and Associated Equipment 420(1-2), 259-263 (2009)

[7] Culler, D., Estrin, D., Srivastava, M.: Overview of sensor networks. Computer 37(8), 4149 (2004)

[8] Drndarevic, V., Jevtic, N.: A versatile, PC-based gamma ray monitor. Radiation Protection Dosimetry 129(4), 478-480 (2009) 
[9] Drndarevic, V., Bolic, M.: Gamma Radiation Monitoring with Internet-Based Sensor Network. Instrumentation Science \& Technology 36(2), 121-133 (2008)

[10] Figaro Engineering Inc., Low power solid state monitoring sensors for toxic, explosive gases and contaminating particles,

http: / /www. figarosensor. com/gaslist.html (accessed on June 14, 2012)

[11] Hart, J.K., Martinez, K.: Environmental Sensor Networks: A revolution in the earth system science? Earth-Science Reviews 78(3-4), 177-191 (2006)

[12] Huang, F.T., Sung, T.: Design and Implementation of Radiation Dose Monitoring System Based on Wireless Sensor Network. In: International Conference on Future Information Technology, IPCSIT, vol. 13, pp. 430-434. IACSIT Press (2011)

[13] Kim, Y.J., Platt, U. (eds.): Advanced Environmental Monitoring. Springer (2008)

[14] Lewis, F.L.: Wireless Sensor Networks. In: Cook, D.J., Das, S.K. (eds.) Smart Environments: Technologies, Protocols and Applications. John Wiley, NY (2004)

[15] Munir, M., Ahmad, N., Sohail, S.: Design and development of a portable gamma radiation monitor. Review of Scientific Instruments 80(7), 073101-073101-6 (2009)

[16] Oliveira, C., Goncalves, G.: Environmental Monitoring Services and wireless sensor networks applied on Urban Spaces. In: Proceedings of the IEEE International Conference on Automation, Quality and Testing, Robotics (AQTR), vol. 3, pp. 1-6 (2010)

[17] Oprea, M., Buruiană, V., Matei, A.: A microcontroller-based intelligent system for realtime flood alerting. International Journal of Computers, Communications \& Control 5(5), 844-851 (2010)

[18] Pon, R., Kansal, A., Liu, D., Rahimi, M., Shirachi, L., Kaiser, W.J., Pottie, G.J., Srivastava, M., Sukhatme, G., Estrin, D.: Networked Infomechanical System (NIMS): Next Generation Sensor Netwokrs for Environmental Monitoring, pp. 373-376. IEEE Computer Society (2005)

[19] Rundel, P.W., Graham, E.A., Allen, M.F., Fisher, J.C., Harmon, T.C.: Environmental sensor networks in ecological research. New Phytologist 182, 589-607 (2009)

[20] Schirru, R., Pereira, C.M.: A Real-Time Artifically Intelligent Monitoring System for Nuclear Power Plants Operators. Support Ingenta Connect Real-Time Systems 27(1), 7183 (2004), doi:10.1023/B:TIME.0000019127.50572.9b

[21] von Storch, H., Tol, R.S.J., Flöser (eds.) Environmental Crises - Science and Policy. Springer (2008)

[22] http://www.marvell.com/embedded-processors/kirkwood/ asset.s/88F6281-004_ver1.pdf (accessed on May 20, 2012)

[23] ftp://ftp.freebsd.org/pub/FreeBSD/releases/sparc64/sparc64/ ISO-IMAGES / 9 . 0 / (accessed on January 4, 2012)

[24] SBM-19 military Geiger Muller sensor datasheet, http: / / www. gstube. com/data/2397/ (accessed on May 20, 2012)

[25] flite text to speech synthesis engine, Carnegie Mellon University, Pittsburgh PA, USA, http: / /www.speech.cs.cmu.edu/flite/ (accessed on August 12, 2010)

[26] Unix PING utility, http://www. freesoft.org/CIE/Topics/53.html (accessed on May 20, 2012) 